\title{
ISOLATION OF VINCANINE
}

Kh. N. Aripov, T. T. Shakirov, and P. Kh. Yuldashev

Khimiya Prirodnykh Soedinenii, Vol. 2, No. 4, pp. 293-294, 1966

Vincanine has been isolated from the roots of Vinca erecta Rg1. et Schmalh. [1]. The content of vincanine in the roots varies from 0.5 to $0.9 \%$. The hydrochloride of this substance is an analeptic for the central nervous system [2,3]. We have investigated the possibility of extracting vincanine from roots with weak solutions of acids (sulfuric, hydrochlor ic, acetic) and water. Good results have been obtained with the use of a $1 \%$ solution of acetic acid. Of the cation ex changers $\mathrm{KU}-1, \mathrm{KU}-2$, and $\mathrm{KB}-4 \mathrm{P}-2, \mathrm{KU}-1$ possesses the greatest exchange capacity with respect to the combined alkaloids of the roots. The extraction process was carried out continuously in a battery of four"extractors combined in series by the flow method. A $1 \%$ solution of acetic acid was passed at the rate of $5 l / \mathrm{hr} .40 l$ of extract was run off from the first extractor, and then the last extractor was disconnected, and one containing fresh roots was placed in place of the first extractor. In this way more than $100 \mathrm{~kg}$ of roots was extracted.

The extract was filtered and passed through a battery of absorbers consisting of three columns with $4.2 \mathrm{~kg}$ of ion exchanger (air-dry) in each. The total thickness of the layer of ion-exchanger was $0.4 \mathrm{~m} \times 3=1.2 \mathrm{~m}$. No alkaloids could be detected in the solution taken from the third absorber. A $1.5 \%$ solution of ammonia in $85 \%$ ethyl alcohol proved to be a good desorbent.

The alcoholic solution obtained from the absorbers was concentrated in vacuum to half bulk and was acidified with concentrated hydrochloric acid. The acidified eluate was evaporated until the alcohol had been completely eliminated. About $17 l$ of the acid solution (residue after the extraction of $100 \mathrm{~kg}$ of roots) was made alkaline with an excess of $30 \%$ caustic soda (to convert the phenolic alkaloid vincanidine into the phenoxide, which is sparingly soluble in chloroform) and was extracted three times with chloroform. The latter was distilled off to dryness in vacuum and the vincanine was isolated by treating the dry residue with acetone. From this base vincanine hydrochloride was obtained.

\section{REF ERENCES}

1. S. Yu. Yunusov and P. Kh. Yuldashev, DAN UzSSR, no. 12, 24, 1952; ZhOKh, 27, $2015,1957$.

2. M. B. Sultanov, Izv. AN UZSSSR, ser. med., no. 3, 38, 1959.

3. M. B. Sultanov, DAN UzSSSR, no. 5, 55, 1962.

3 March 1966

Institute of the Chemistry of Plant Substances, AS UzSSR

GENERAL METHOD OF OBTAINING $5^{\circ}-0-(\alpha-A L K O X Y A L K Y L)-D E R I V A T I V E S$ OF NUCLEOTIDES

\section{S. M. Zhenodarova and E. A. Sedel'nikova}

Khimiya Prirodnykh Soedinenii, Vol. 2, No. 4, pp. 294-295, 1966

We have previously reported that $5^{\prime}-0-\left(\alpha\right.$-butoxyethyl) uridine $3^{\prime}$-phosphate $[1,2]$ and $2^{\prime}-0-(\alpha$-ethoxyethyl)5) -O-acetyluridine $3^{\prime}$-phosphate [3] are of interest as intermediates in the synthesis of oligonucleotides. These compounds were obtained by the treatment of uridine $3^{\prime}$-phosphate and $5 '-0$-acetyluridine $3^{\prime}$-phosphate, respectively, with vinyl butyl ether and vinyl ethyl ether, respectively.

In the present paper we propose the use, as a more general method of synthesis of $5^{\prime}-0-(\alpha-a l k o x y a l k y l)$ de rivatives of nucleotides, of the reaction for obtaining mixed acetals from an aldehyde and a mixture of alcohols [4].<smiles>[R]OC(=[R])O[R20]</smiles> 